\title{
Sequência didática para o ensino inclusivo de estudantes com deficiência visual: abordagem do tema abelhas
}

\author{
Fabiana Gomes Guntzel*, Franciele Braz de Oliveira Coelho**
}

\section{Resumo}

A inclusão no âmbito escolar descende de muitos estudos e práticas que assegurem o direito dos estudantes de construírem seus conhecimentos juntos. Para que esse direito seja garantido, a escola deve oportunizar meios didático-pedagógicos para esse processo inclusivo acontecer, buscando valorizar a heterogeneidade, tratando a todos com o princípio da equidade. Este trabalho relata uma pesquisa desenvolvida em um curso de Ciências da Natureza Licenciatura, a qual objetivou investigar a pertinência da aplicação de uma sequência didática sobre a temática abelhas, no componente curricular de Ciências na Educação Básica. A metodologia se caracterizou, quanto à abordagem, como qualitativa; quanto aos objetivos, exploratória e, quanto aos procedimentos, como intervenção pedagógica. Teve como lócus uma escola da rede pública municipal e o sujeito uma estudante com deficiência visual matriculada no sétimo ano da escola. Os dados foram analisados segundo a metodologia de Linguagem de Descrição (BERNSTEIN, 2000). A pesquisa foi desenvolvida em quatro etapas, para melhor elucidação sobre o contexto pesquisado. Como resultados, o estudo apresentou que a inclusão de estudantes com deficiência visual no contexto escolar é uma realidade possível e o uso de materiais e recursos adequados, elaborados a partir dos interesses, necessidades, potencialidades e da realidade dos sujeitos, facilitam a interação em sala de aula, propiciando seu desenvolvimento pessoal por meio do estímulo na busca pela construção do conhecimento.

Palavras-chave: Ensino de Ciências da Natureza; Aprendizagem significativa; Inclusão escolar.

* Licenciada em Ciências da Natureza pela Universidade Federal do Pampa (Unipampa) - Campus Dom Pedrito. Mestranda do PPG em Ensino de Ciências da Unipampa - Campus Bagé, Brasil. E-mail: fabiguntzel@gmail.com.

** Doutora em Ensino de Ciências pela Universidade Franciscana (UFN). Professora Adjunta da Universidade Federal do Pampa (Unipampa) - Campus Dom Pedrito, Brasil. E-mail: francielecoelho@unipampa.edu.br.

Recebido em: 28/05/2020; Aceito em: 29/01/2021

https://doi.org/10.5335/rbecm.v4i2.11099

http://creativecommons.org/licenses/by-nc-nd/4.0

ISSN: 2595-7376 


\section{Introdução}

A Educação é um direito garantido pela Constituição a todos e a qualquer ser humano, cujo princípio fundamental da escola inclusiva é o de que todos os estudantes devem aprender juntos, sempre que possível, independentemente de quaisquer dificuldades ou diferenças que possam ter. Assim, a inclusão se torna um desafio nos processos de ensino e aprendizagem nas salas de aulas regulares, não apenas aos estudantes incluídos, mas também aos professores que, muitas vezes, não se sentem preparados para uma efetiva inclusão no processo educacional.

Sobre o conceito de inclusão, Mantoan (2005, p. 24) a define como “[...] a nossa capacidade de entender e reconhecer o outro e assim, ter o privilégio de conviver e compartilhar com pessoas diferentes de nós". No que se refere às práticas sociais, a sociedade, em suas diferentes culturas, atravessou diversas fases, como relata Sassaki (2010, p. 16), começando pela exclusão social de pessoas que, por suas "[...] condições atípicas não pertenciam à maioria da população". Desenvolveu-se nesse contexto o atendimento segregado dentro de instituições, passando à prática da integração social e, recentemente, a sociedade adota a filosofia da inclusão social para modificar os sistemas sociais gerais. Nesse âmbito, cabe destacar a necessidade de "[...] modificação da sociedade como pré-requisito para qualquer pessoa buscar e exercer a cidadania" (SASSAKI, 2010, p. 42).

A área de Ciências da Natureza carece de pesquisas que contemplem o ensino inclusivo a estudantes com deficiência visual (DV). Em análise realizada nas atas do Encontro Nacional de Pesquisa em Educação em Ciências (ENPEC), evento de grande porte e de relevância para a área, verificou-se que, em suas 12 edições, período de 1997 a 2019, apesar do expressivo número de publicações, sobre a temática, a primeira publicação ocorreu no evento apenas no ano de 2001, em um montante de 233 publicações da edição. Nas edições seguintes, verifica-se pelo menos um trabalho com foco na DV, número ainda pouco expressivo diante das dimensões do evento.

Tendo em vista a importância do processo inclusivo, o presente estudo contemplou o tema inclusão envolvendo estudantes com DV e a importância do professor de Ciências da Natureza frente a essa temática. Sabe-se que os fundamentos teóricos metodológicos da inclusão escolar estão centrados em uma concepção de Educação de qualidade para todos, destacando o respeito à diversidade dos educandos e a importância da preparação de profissionais e educadores ao atendimento das pessoas com deficiência. 
Considerando o processo inclusivo de estudantes com deficiência visual na Educação Básica, a proposta deste estudo visou investigar a pertinência da aplicação de uma sequência didática (SD) sobre a temática abelha, no componente curricular de Ciências na Educação Básica. As atividades que fazem parte da SD são organizadas de maneira a aprofundar o tema que está sendo estudado e são variadas em termos de estratégia: leituras, aula dialogada, simulações, jogos didáticos, atividades práticas experimentais, etc. (ZABALA, 1998).

A temática sobre abelhas com enfoque na produção de mel foi escolhida para a confecção da SD, uma vez que o Estado do Rio Grande do Sul, local de desenvolvimento da pesquisa, é o principal produtor de mel do país ${ }^{1}$ e o município de sua aplicação tem relevante número de apicultores, favorecendo o entendimento sobre o assunto e despertando o interesse dos estudantes.

A partir do exposto, emergiu o seguinte problema de pesquisa: De que forma a proposição de uma sequência didática acessível para estudantes com deficiência visual contribui para a apropriação dos conceitos científicos relacionados a animais invertebrados - classe insecta?

Cabe ressaltar a importância da diversificação de atividades e recursos didáticos no processo de inclusão escolar,

[...] é diversificando as atividades, trabalhando conteúdos e utilizando recursos alternativos que se consegue a participação ativa do aluno no processo ensino-aprendizagem e, consequentemente, o seu crescimento pessoal, de forma que possa aplicar e utilizar os conhecimentos adquiridos na prática social (POLICARPO, 2008, p. 08).

São de fundamental importância a utilização de metodologias e recursos específicos nos processos de ensino e aprendizagem os quais favoreçam uma aprendizagem ativa em algum grau, exigindo do estudante e do professor formas diferentes de movimentação interna e externa (MORAN, 2015). É nesse contexto que se faz necessário empregar metodologias adaptadas no processo educacional inclusivo, de modo a suprir as inúmeras barreiras existentes no ensino e na aprendizagem de Ciências da Natureza.

Atualmente, o ensino de Ciências da Natureza, a partir da Base Nacional Comum Curricular (BNCC) (BRASIL, 2017) está estruturado em eixos temáticos que organizam seus conteúdos no decorrer do Ensino Fundamental. Com o objetivo de proporcionar aos estudantes o contato com processos, práticas e procedimentos de modo a intervir na sociedade, a BNCC traz inúmeros desafios, incluindo a investi- 
gação nos processos de ensino e aprendizagem e o desenvolvimento do letramento científico, que envolve a capacidade de compreender e interpretar o mundo (natural, social e tecnológico), mas também de transformá-lo com base nos aportes teóricos e processuais das ciências (BRASIL, 2017).

Apreender Ciências, de acordo com esse documento, não é a finalidade última do letramento científico, mas o desenvolvimento da capacidade de atuação do estudante no e sobre o mundo. É importante destacar o papel do professor como mediador nas ações investigativas de modo a "[...] fortalecer a autonomia dos estudantes, oferecendo-lhes condições e ferramentas para acessar e interagir criticamente com diferentes conhecimentos e fontes de informação" (BRASIL, 2017, p. 60).

Nesse contexto, os recursos didáticos acessíveis e recursos de tecnologias assistivas assumem fundamental importância na educação de estudantes cegos, oportunizando o acesso à aprendizagem de conceitos científicos.

\section{Materiais didáticos e tecnologias assistivas no ensino de estudantes com deficiência visual}

Muitas terminologias são utilizadas como sinônimos da tecnologia assistiva (TA), dentre elas: ajudas técnicas, tecnologias de apoio, tecnologia adaptativa e adaptações (LAVORATO, 2014). Para Mól (2019, p. 133), o conceito de TA “[...] diz respeito a uma ampla gama de produtos e serviços, pois no senso comum estaria ligada a equipamentos digitais, softwares e informática". O autor destaca ainda que a TA vai além desse conceito, estando presente em simples adaptações como um lápis mais grosso, material em relevo, dentre outros.

A TA, para um estudante cego, é o que supre suas deficiências específicas decorrentes da ausência da visão, proporcionando-lhe autonomia no desempenho de atividades diárias (GALVÃO FILHO, 2013). O termo TA é uma expressão que se refere a um conceito ainda em processo de construção, cuja utilização de recursos se reporta aos primórdios da história da humanidade.

No Ensino de Ciências da Natureza, o uso desses recursos possibilita a habilidade de desenvolver materiais que empreguem uma didática multissensorial, utilizando outros sentidos do corpo humano como meio de veiculação da informação, como o tato e a audição, de forma individual ou mista (CAMARGO, 2012). Sendo o Ensino de Ciências da Natureza baseado grande parte em conceitos representados visual- 
mente por meio de equações e/ou experimentos, o professor deve utilizar recursos acessíveis que promovam a aprendizagem dos alunos com DV.

[...] é incompreensível que os estudantes com deficiência visual tenham grandes dificuldades com a sistemática do ensino atual visto que o mesmo invariavelmente fundamenta-se em referenciais funcionais visuais (CAMARGO; SILVA, 2003, p.1218).

No contexto de inclusão social visando à autonomia, independência e qualidade de vida surge a necessidade de utilização de materiais e recursos didáticos que favoreçam a aprendizagem do estudante com deficiência. Há inúmeras possibilidades de utilizar materiais simples e de baixo custo para a mediação dos processos de ensino e aprendizagem, os quais devem ser explorados à abordagem de conceitos. Ao utilizar um recurso de TA em sala de aula, o professor deve considerar o impacto dessa provisão da TA às reais necessidades dos estudantes com deficiência visual, a avaliação funcional dos recursos utilizados se faz necessária para que a aprendizagem aconteça.

\section{contexto para uma aprendizagem significativa}

Diante da complexidade do processo de inclusão escolar envolvendo desde a legislação, o Ensino de Ciências da Natureza para pessoas com deficiência visual, a formação de professores, a disponibilidade de recursos de TA, é importante a discussão acerca da aprendizagem de um estudante com DV. No contexto da sala de aula em meio a tantas diferenças, o professor será o mediador do processo e todos devem ser incluídos em seu planejamento evitando assim, o desconforto que um estudante com deficiência enfrenta diante da escolarização.

De acordo com Galery (2017, p.14), “[...] aprender é parte da condição humana é seu órgão de sobrevivência”. Na qual essa condição de aprender para sobreviver demande de uma relação afetiva com o outro conduzindo aos desafios da vida por meio de laços sociais. Para que a aprendizagem significativa ocorra, é preciso haver um processo de modificação do conhecimento, reconhecendo a importância que os processos mentais têm nesse desenvolvimento.

Destacando a importância da mediação do professor nos processos de ensino e aprendizagem, possibilitando ao estudante com DV reorganizar os conceitos já existentes com os conceitos mediados em sala de aula até a assimilação deles, torna-se importante as contribuições de Vygotsky e a influência de seus conceitos 
no processo inclusivo. Para Vygotsky (2007), a relação do homem com o ambiente em que vive não é realizada de maneira direta, mas caracterizada pela presença de um mediador. Dessa forma, Vygotsky (2007) destaca que a mediação estabelece as relações do homem com o mundo e elas vão se constituindo ao longo da vida. $\mathrm{O}$ autor destaca a importância de pessoas com DV no contexto escolar, pois, ao estabelecer relações com estudantes videntes, haveria a mediação de suas relações com o ambiente em que está incluído (VYGOTSKY, 2001).

\section{Abordagem metodológica}

Quanto à natureza da pesquisa, este estudo se caracterizou como qualitativo, pois, segundo Triviños (1987), essa abordagem trabalha os dados buscando seu significado, tendo como base a percepção do fenômeno dentro do seu contexto. Em relação aos objetivos propostos, a pesquisa foi exploratória, sendo que estudos com este viés têm como objetivo principal desenvolver, esclarecer e modificar conceitos e ideias, tendo em vista a formulação de problemas mais precisos ou hipóteses pesquisáveis para estudos posteriores (GIL, 1999). Quanto à escolha do objeto de estudo, classifica-se como intervenção pedagógica. Conforme Gil (2002), essas pesquisas têm por objetivo ampliar os conhecimentos, preocupando-se com seus possíveis benefícios práticos. No estudo em questão, buscou-se analisar o contexto da inclusão na escola por meio do uso de sequência didática no Ensino de Ciências da Natureza, de forma que esse cenário fosse investigado em sua totalidade.

A pesquisa foi aplicada em uma turma com uma estudante com deficiência visual incluída no sétimo ano do Ensino Fundamental, em uma escola pública municipal pertencente à zona urbana, de um município localizado na região da Campanha Gaúcha. A pesquisa fez uso de observações como coleta de dados para conseguir informações sobre determinados aspectos da realidade, ajudando a pesquisadora a "[...] identificar e obter provas a respeito de objetivos sobre os quais os indivíduos não têm consciência, mas que orientam seu comportamento" (LAKATOS; MARCONI, 1996, p. 79).

A escola participante da pesquisa é uma instituição nucleada do município, recebendo estudantes tanto da zona urbana como rural, desde a Educação Infantil até o nono ano do Ensino Fundamental, totalizando 190 estudantes matriculados na instituição. A escola tem uma profissional especialista que atende na sala de recursos multifuncionais para atendimento educacional especializado (AEE). 


\section{Ełapas de desenvolvimento da pesquisa}

Este estudo foi desenvolvido em quatro etapas, descritas e apresentadas na Figura 1:

Figura 1: Etapas do desenvolvimento da pesquisa.

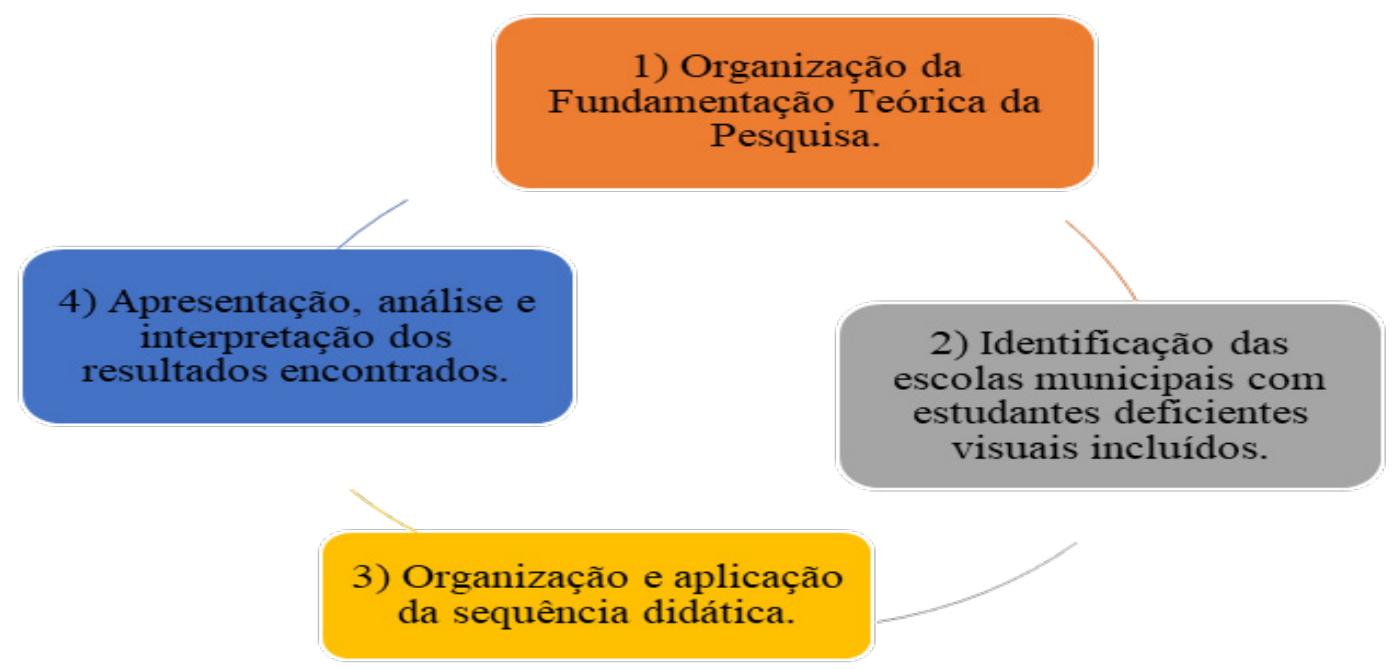

Fonte: Autoras (2019).

De acordo com a análise realizada nas escolas municipais participantes da pesquisa, apenas uma apresentava uma estudante com baixa visão incluída nos anos finais do Ensino Fundamental, enquadrando-se nos objetivos propostos à realização da pesquisa. No estudo foram utilizados os seguintes instrumentos de coleta de dados: diário de campo, observações e questionários. O questionário foi aplicado à professora de Ciências que tem uma estudante com baixa visão incluída no sétimo ano; à professora especialista responsável pelo atendimento na sala de atendimento educacional especializado (AEE) e à estudante com baixa visão participante da pesquisa. A todos os participantes da pesquisa foi solicitada a assinatura de termo de consentimento livre e esclarecido e seus nomes não foram divulgados, a fim de resguardar suas identidades. Na etapa de aplicação da sequência didática para a turma da estudante incluída, também foram utilizados como instrumentos a observação e o diário de campo.

A metodologia para análise dos dados foi a da Linguagem de Descrição (BERNSTEIN, 2000). O autor destaca dois tipos de linguagem: a linguagem de descri- 
ção interna, que compreende a teoria (ou conjunto de teorias) e seus conceitos e a linguagem de descrição externa, representada pelos modelos gerados a partir da linguagem de descrição interna. A seguir, tem-se a representação em diagrama da metodologia de Bernstein utilizada para a análise dos dados.

Figura 2: Metodologia de Linguagem de descrição para análise dos dados.

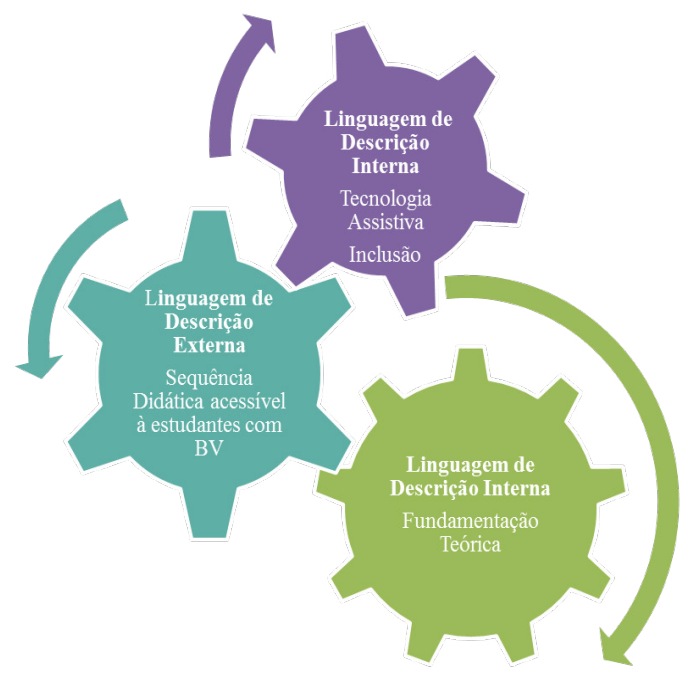

Fonte: Adaptado de Bernstein (2000).

Segundo Bernstein (2000), esta metodologia visa favorecer uma relação dialética entre os conceitos constituídos por uma teoria (linguagem de descrição interna) e os dados empíricos a serem analisados (linguagem de descrição externa). A partir de mudanças originadas pelos dados empíricos, a linguagem de descrição externa conduz a mudanças na linguagem de descrição interna.

\section{Metodologia de trabalho: sequência didática}

A sequência didática (SD) foi elaborada abordando conteúdos referentes a diferentes áreas do conhecimento como: Química, Física, Biologia, Matemática e Língua Portuguesa, fugindo da fragmentação dos conteúdos e permitindo ao professor desenvolver conceitos científicos de um modo dinâmico, tornando as aulas de Ciências mais atraentes e significativas. A SD parte de uma introdução sobre a atividade de apicultura e a produção de mel no município pesquisado, logo, são 
discutidos os conceitos sobre a sociedade dessa espécie na colmeia para a produção de mel, destacando as características morfológicas das abelhas e as características do favo de mel. São abordados também conceitos referentes ao processo de polinização destacando a importância da espécie para o meio ambiente, bem como o risco de extinção dela devido ao uso de agrotóxicos.

Diferentes materiais didáticos foram utilizados para a abordagem dos conceitos: álbum seriado, jogo didático e maquetes táteis. Para que o material fosse acessível a todos os estudantes, a letra foi ampliada em fonte arial tamanho 24, conforme orientações da professora especialista da sala de atendimento educacional especializado (AEE) da escola participante da pesquisa. O material se torna acessível também a estudantes cegos, embora não tivesse esse público incluído no contexto da pesquisa, sendo essencial adaptá-lo a essa necessidade. $\mathrm{O}$ álbum seriado tem fonte ampliada e escrita em braile, as imagens também são ampliadas e com diferentes texturas para que todos os estudantes tenham acesso ao mesmo material didático.

Figura 3: Capa do álbum seriado adaptado e de página interior mostrando o favo de mel com texturas
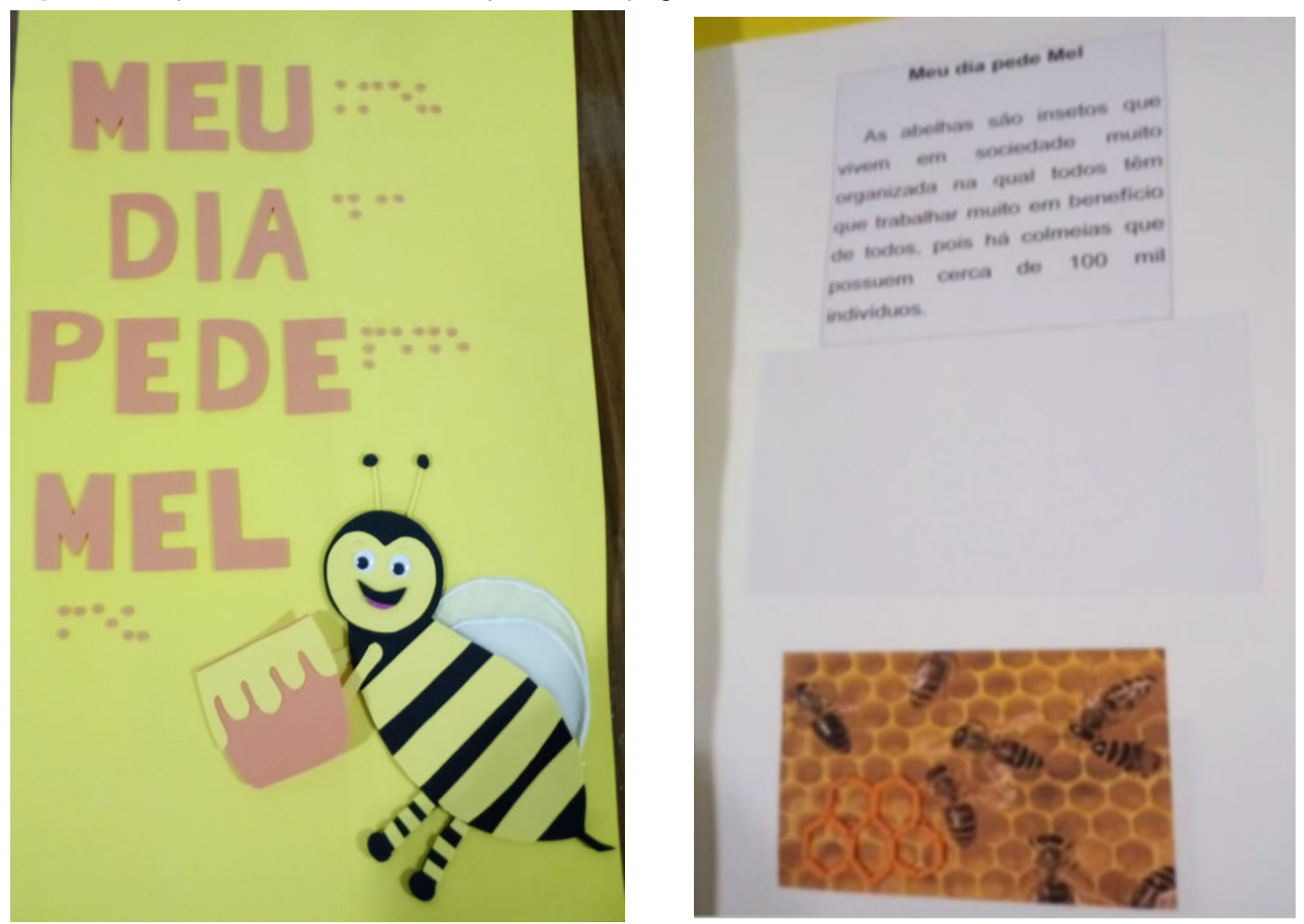

Fonte: Autoras (2019). 
O jogo associação das abelhas (Figura 4) tem o objetivo de relacionar fichas com as características das abelhas: operária, rainha e zangão e suas funções na colmeia.

Figura 4: Jogo Associação das Abelhas.

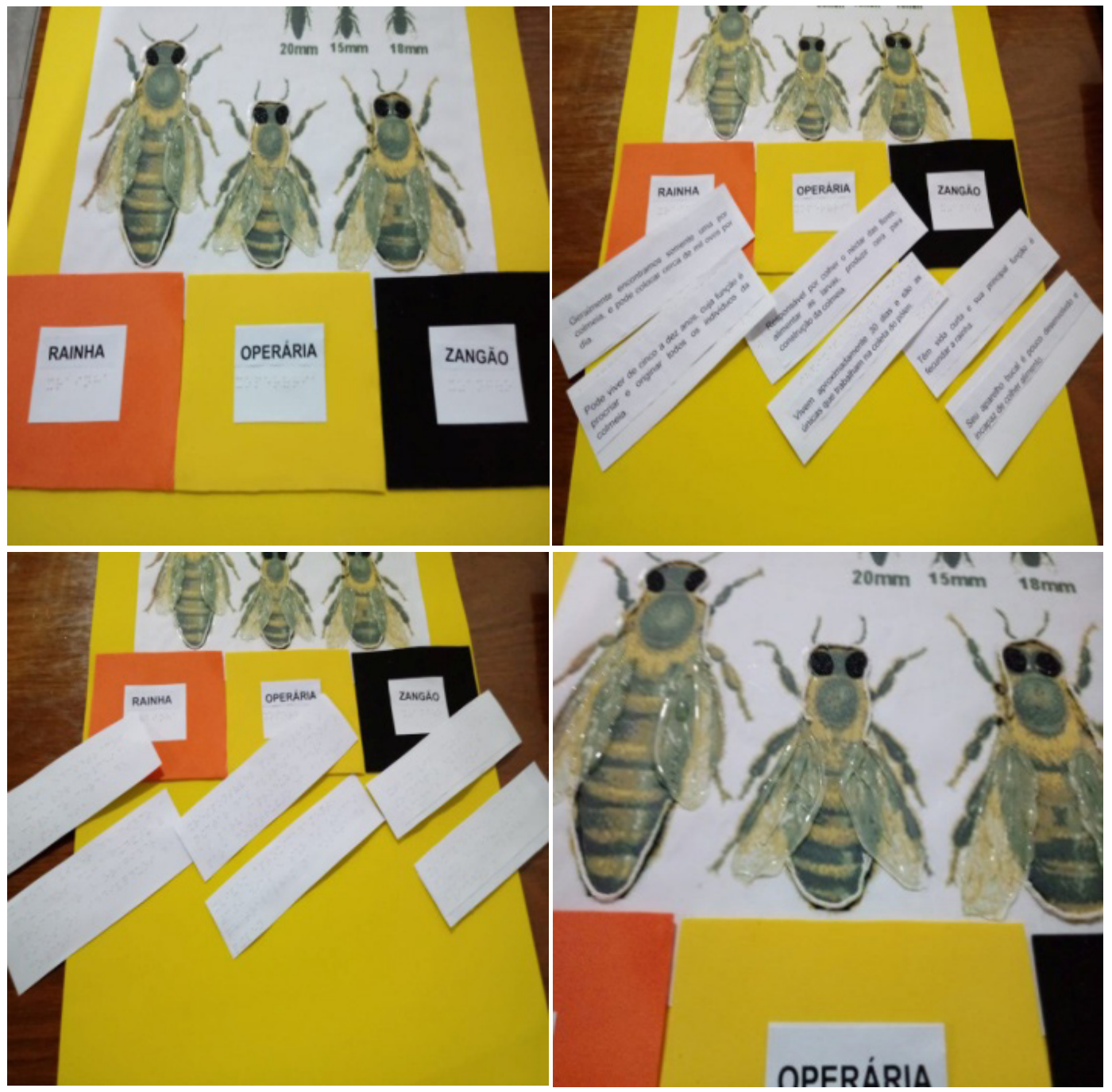

Fonte: Autoras (2019).

Os conceitos referentes à morfologia foram abordados por meio de associação das partes que constituem o corpo das abelhas em maquete tátil da imagem da abelha, ampliada e com diferentes texturas (Figura 5). As fichas apresentam fonte ampliada e também a escrita em braile. 
Figura 5: Maquete tátil para associação das partes morfológicas das abelhas.
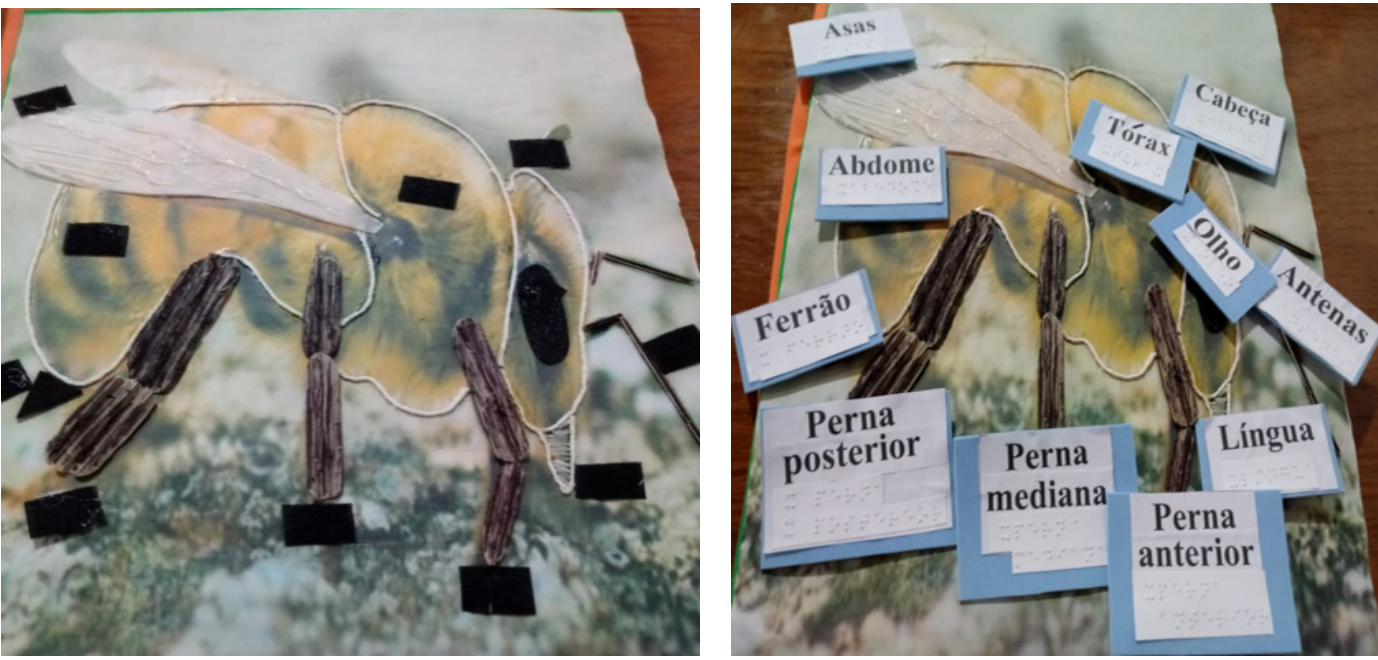

Fonte: Autoras (2019).

Para identificar os principais produtores nacionais de mel, foi utilizado um mapa tátil, confeccionado em diferentes texturas (Figura 6).

Figura 6: Mapa tátil.

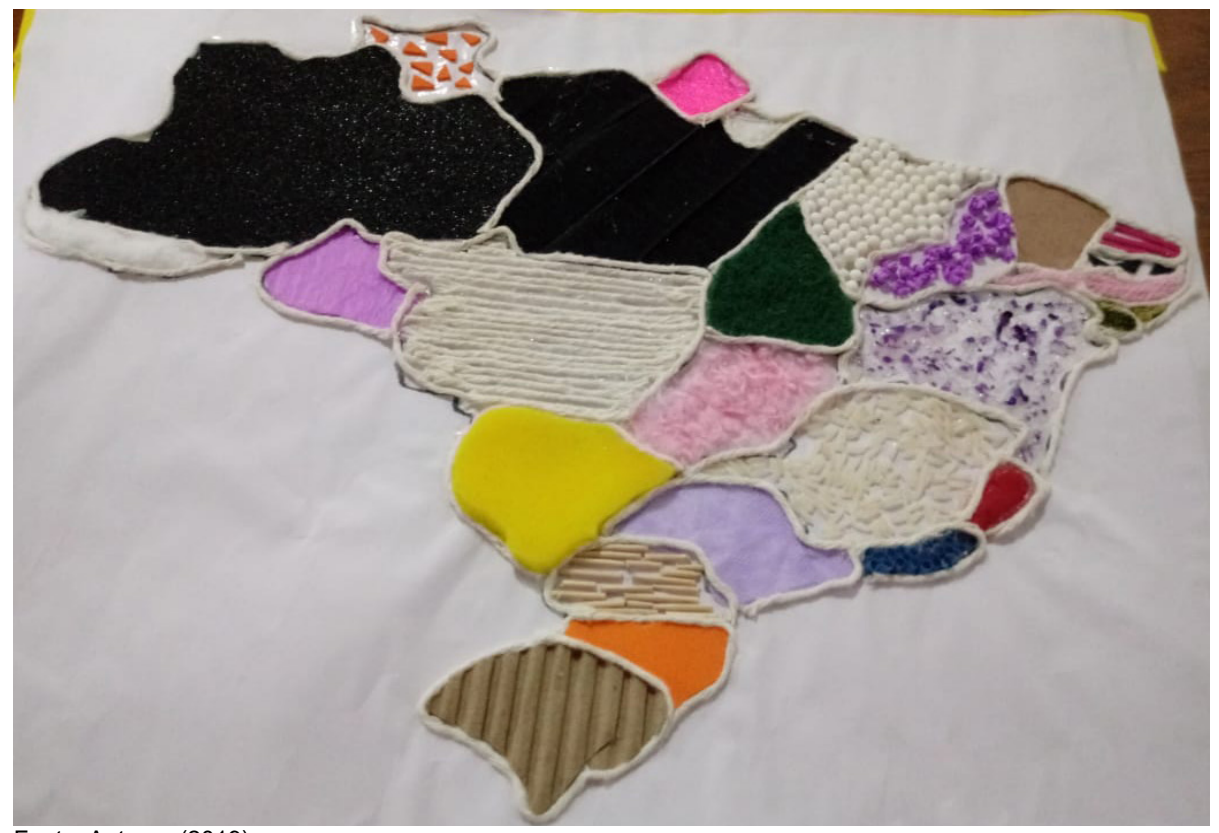

Fonte: Autoras (2019) 
O jogo caminho das abelhas, presente na $\mathrm{SD}$, tem como objetivo identificar conceitos fundamentais referentes à organização social das abelhas, à polinização e à produção de mel e ao impacto por meio do uso de agrotóxicos e desmatamento, ocasionando a diminuição de indivíduos dessa espécie. Os materiais utilizados para a realização do jogo são um tabuleiro ampliado e adaptado em braile, com textura demarcando o espaço das "casas", dado com números ampliados e escrita numérica em braile, dois pinus com diferentes texturas e questões com fonte ampliada e escrita em braile, conforme Figura 7.

Figura 7: Jogo Caminho das Abelhas
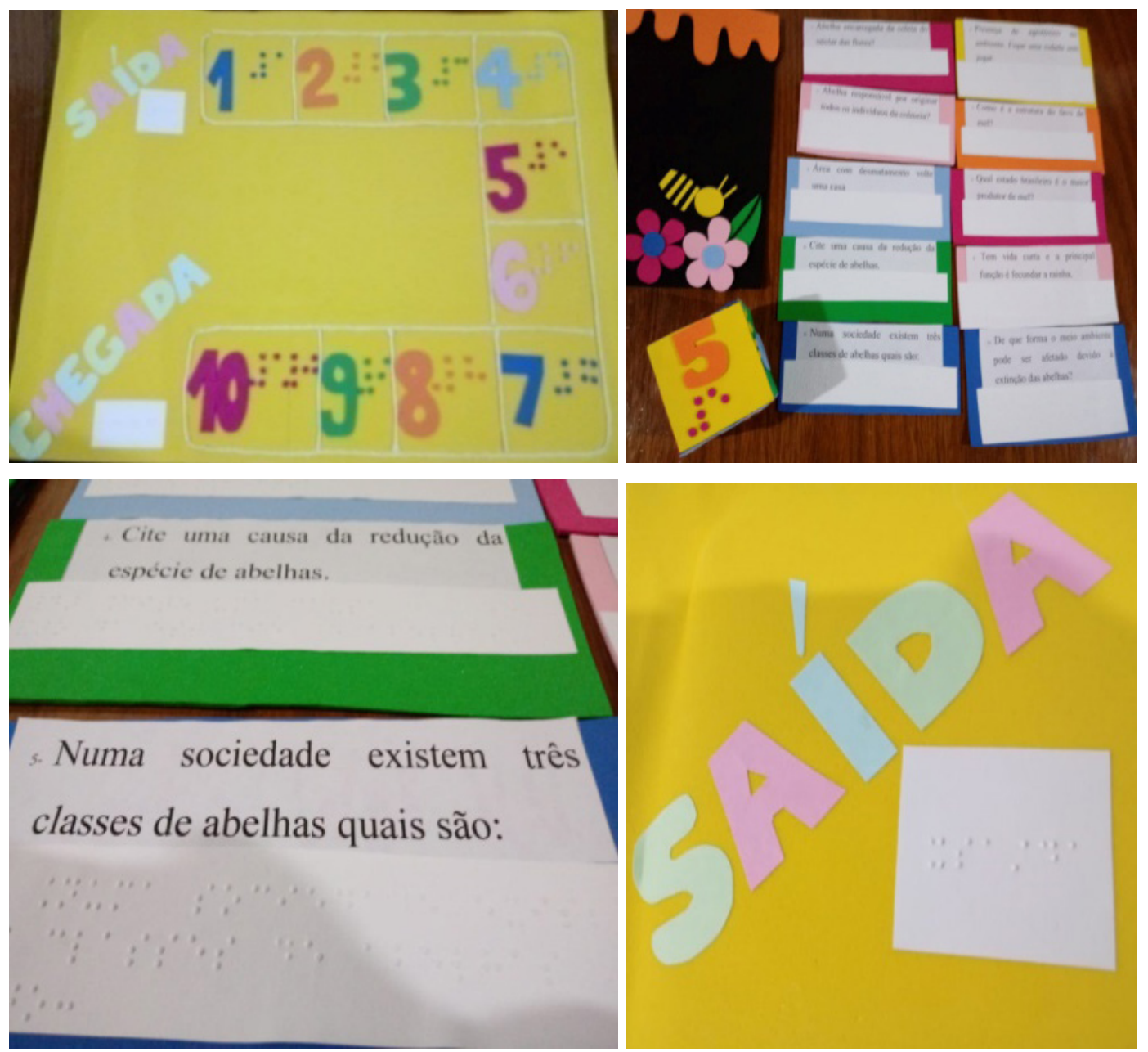

Fonte: Autoras (2019). 
A sequência didática foi adaptada para estudantes com deficiência visual (baixa visão ou cegueira), e foi aplicada em uma turma de sétimo ano do Ensino Fundamental da rede municipal de ensino, que continha uma estudante com baixa visão. Os materiais que compõem a SD foram utilizados por todos os estudantes da turma, mostrando a importância do uso de diferentes materiais que possibilitem o processo de inclusão em sala de aula.

\section{Resultados e discussões}

O campo teórico permeou a coleta de dados, da mesma forma que os dados coletados possibilitaram o enriquecimento das teorias adotadas, em processo dialético. No Quadro 1, tem-se o detalhamento da análise dos dados:

Quadro 1: Análise de dados da pesquisa, conforme Bernstein (2000)

\begin{tabular}{|c|c|c|c|}
\hline Etapa & Procedimento & $\begin{array}{l}\text { Linguagem de descrição } \\
\text { interna }\end{array}$ & $\begin{array}{c}\text { Linguagem de } \\
\text { descrição externa }\end{array}$ \\
\hline $\begin{array}{l}\text { - Identificar os materiais didático- } \\
\text {-pedagógicos e os recursos didáticos } \\
\text { utilizados na sala de atendimento } \\
\text { educacional especializado (AEE) da } \\
\text { escola participante do estudo; } \\
\text { - Compreender o trabalho desenvolvi- } \\
\text { do na sala de AEE voltado aos estu- } \\
\text { dantes com deficiência visual. }\end{array}$ & $\begin{array}{l}\text { Entrevista e aplica- } \\
\text { ção de questionário } \\
\text { - profissional respon- } \\
\text { sável pelo AEE da } \\
\text { escola. }\end{array}$ & $\begin{array}{l}\text { Principais referenciais sobre } \\
\text { inclusão: Bersch (2017), Ga- } \\
\text { lery (2017) e Mól (2019). }\end{array}$ & $\begin{array}{l}\text { Resultados obti- } \\
\text { dos com a entre- } \\
\text { vista e o questio- } \\
\text { nário. }\end{array}$ \\
\hline $\begin{array}{l}\text { - Analisar a metodologia utilizada pela } \\
\text { professora para o ensino de Ciências } \\
\text { da Natureza junto à estudante com } \\
\text { deficiência visual em sala de aula. }\end{array}$ & $\begin{array}{l}\text { Entrevista e questio- } \\
\text { nário aplicados à pro- } \\
\text { fessora de Ciências } \\
\text { da Natureza. }\end{array}$ & $\begin{array}{l}\text { Metodologia ativa: } \\
\text { Lilian Bacich e José Moran } \\
(2018) \\
\text { Inclusão: } \\
\text { Romeu Kazumi Sassaki } \\
\text { (2010) e Gerson Mól (2019) }\end{array}$ & $\begin{array}{l}\text { Resultados obti- } \\
\text { dos com a aplica- } \\
\text { ção dos questio- } \\
\text { nários. }\end{array}$ \\
\hline $\begin{array}{l}\text { Sequência didática de Ciências da } \\
\text { Natureza que possibilite a inclusão da } \\
\text { estudante com deficiência visual no } \\
\text { contexto escolar. }\end{array}$ & $\begin{array}{l}\text { Reorganizar e aplicar } \\
\text { sequência didática } \\
\text { para a turma com a } \\
\text { estudante com defici- } \\
\text { ência visual incluída. }\end{array}$ & $\begin{array}{l}\text { Metodologia ativa: } \\
\text { Lilian Bacich e José Moran } \\
\text { (2018) } \\
\text { Sequência didática: } \\
\text { Zabala (1998) } \\
\text { Inclusão: } \\
\text { Romeu Kazumi Sassaki } \\
\text { (2010) e Gerson Mól (2019) }\end{array}$ & $\begin{array}{l}\text { Material didático } \\
\text { construído. }\end{array}$ \\
\hline $\begin{array}{l}\text { Avaliar o processo de construção do } \\
\text { conhecimento da estudante com de- } \\
\text { ficiência visual com a aplicação da } \\
\text { sequência didática. }\end{array}$ & $\begin{array}{l}\text { - Entrevista e questio- } \\
\text { nário aplicados à es- } \\
\text { tudante incluída par- } \\
\text { ticipante da pesquisa. } \\
\text { - Anotações do diário } \\
\text { de campo da pesqui- } \\
\text { sadora. } \\
\text { - Observações. }\end{array}$ & $\begin{array}{l}\text { Metodologia ativa: } \\
\text { Lilian Bacich e José Moran } \\
\text { (2018) } \\
\text { Inclusão: } \\
\text { Romeu Kazumi Sassaki } \\
\text { (2010) e Gerson Mól (2019) }\end{array}$ & $\begin{array}{l}\text { Resultados obti- } \\
\text { dos com a entre- } \\
\text { vista, o questioná- } \\
\text { rio e os registros } \\
\text { do diário de campo } \\
\text { e as observações } \\
\text { realizadas pela } \\
\text { pesquisadora. }\end{array}$ \\
\hline
\end{tabular}

Fonte: Construído a partir da teoria de Linguagem de Descrição de Bernstein (2000). 
Conforme exposto, todas as etapas da pesquisa foram delineadas com ambas as linguagens de descrições: interna e externa. Os conceitos de inclusão e recursos acessíveis nos processos de ensino e aprendizagem também foram correlacionados em cada etapa com as ideias descritas por Bernstein (2000). Assim, o estudo buscou compreender a relação entre o processo inclusivo da estudante com deficiência visual nas aulas de Ciências através da aplicação de uma sequência didática.

Como resultado da primeira etapa da pesquisa, que envolveu a participação da professora responsável pela sala de $\mathrm{AEE}$, verificaram-se os inúmeros atendimentos realizados na escola, sendo estes organizados conforme disponibilidade de horário e em turno inverso ao que os estudantes estão na sala de aula. A profissional tem graduação em Pedagogia com habilitação em Orientação Escolar e Educação Especial, especialização em Inclusão e Atendimento Educacional Especializado. Há parceria no trabalho desenvolvimento pelo AEE com alguns professores da escola. As instituições que auxiliam no processo pedagógico para o desenvolvimento do trabalho na escola são o Núcleo de Apoio Psicopedagógico e Inclusivo (NAPI), a Associação de Pais e Amigos dos Excepcionais (APAE) e a fonoaudióloga do município.

Sobre o processo de inclusão em sala de aula, a professora do AEE relata que: "[...] Percebo que já houve uma evolução, mas ainda precisa ser efetivada de fato a inclusão de todos, pois esse processo depende muito do professor na sala de aula em buscar atividades que sejam acessíveis para todos" (Professora responsável pela sala de AEE). Ela também relata a importância do apoio de inúmeros setores municipais para que a inclusão aconteça, oferecendo suporte clínico e pedagógico para que os encaminhamentos sejam realizados e os direitos das pessoas com deficiência garantidos. De acordo com Mól (2019, p. 92) o atendimento educacional especializado apresenta, dentre seus principais objetivos: “[...] Prover condições de acesso, participação e aprendizagem no ensino regular e garantir serviços de apoio especializados de acordo com as necessidades individuais dos estudantes". Nesse sentido, também cabe ressaltar que se faz necessário "Fomentar o desenvolvimento de recursos didáticos e pedagógicos que eliminem as barreiras nos processos de ensino e aprendizagem" (BRASIL, 2011, p. 1).

Como descreve a professora responsável pelo AEE, percebe-se a dificuldade dos professores atuantes em sala de aula em atender às necessidades dos estudantes com deficiência. Há muitas barreiras a serem vencidas e a atuação do professor em sala de aula ainda é a maior quando se trata de uma formação para uma efetiva 
inclusão escolar. Galery (2017, p. 86) destaca a importância da prática docente: “[...] a ação reflexiva da prática docente mobiliza-me cada vez mais para a necessidade de nos unir na construção de uma escola para todos e cada um. Onde todos têm os mesmos direitos e de fato a aprendizagem aconteça".

Nesse contexto reflexivo sobre a prática docente em sala de aula, enfatiza-se a importância da utilização de tecnologias assistivas (TA) que atendam às necessidades dos estudantes incluídos e professores capazes contemplarem o processo inclusivo em seus planejamentos. A utilização da TA, na visão de Bersch (2017), visa auxiliar os estudantes atendidos na sala de recursos em atividades da vida diária e prática, por meio de materiais pedagógicos que atendam às necessidades deles. Bersch (2017) destaca a importância das TA possibilitando estratégias que valorizem a individualidade do estudante aumentando sua capacidade de ação e interação. A professora do AEE da escola busca atuar de forma criativa, procurando alternativas que favoreçam o entendimento de conceitos pelos estudantes por meio de diferentes recursos que permitam autonomia no processo de aprendizagem.

A escola da pesquisa contava em seu corpo docente com uma professora de Ciências com graduação em Ciências do 1. $\square$ grau. Ela atuava com duas estudantes incluídas nos anos finais do Ensino Fundamental: uma estudante surda e uma estudante com baixa visão. O processo de inclusão em sala de aula é destacado pela professora como um desafio, sendo difícil articular a prática do seu planejamento às necessidades das estudantes incluídas em sala de aula. Em entrevista, esta profissional destacou que "[...] utilizo muito em minhas aulas o livro didático, o que dificulta a visualização do conteúdo para a estudante que tem baixa visão, pois a fonte não é ampliada e muitas vezes tenho que atendê-la individualmente" (Relato da professora de Ciências sobre a prática em sala de aula).

A falta de formação necessária para desenvolver um melhor trabalho acaba dificultando o processo, que é amenizado pelo atendimento em turno inverso na sala de AEE, único incentivo à prática inclusiva na escola. É importante destacar até que ponto o atendimento na sala de AEE supre as necessidades nos processos de ensino e aprendizagem de Ciências, uma vez que conceitos científicos precisam ser desenvolvidos. Costa e Lorenzetti (2020, p. 43) destacam que "O domínio conceitual é importante no ensino de ciências, mas é crucial que os alunos transcendam a abstração, sendo capazes de aplicar o conhecimento em seu contexto sociocultural e ambiental. É imprescindível a apropriação do conhecimento para o posicionamento 
crítico frente a problemas científico". Para que isso ocorra de maneira favorável, precisa existir um trabalho colaborativo entre a professora da sala de AEE e a professora de Ciências, ambas desenvolvendo ações capazes de colaborarem significativamente à aprendizagem dos estudantes incluídos. Na escola pesquisada, não ocorria essa união entre as áreas.

Nem sempre o ensino formal atende os objetivos para o Ensino de Ciências. Há necessidades de mudanças indicando que várias situações precisam ser corrigidas, a formação docente, tempo de aprendizagem, a interdisciplinaridade e, no caso da educação inclusiva, a adaptação de recursos (MÓL, 2019). Em relação à atuação do professor em sala de aula, cabe destacar que é necessário "[...] (re) afirmar que a postura do professor transmissor de informações deve dar lugar à postura de mediador entre o sujeito e o objeto de conhecimento, parece ser redundante e insuficiente aos anseios daqueles que estão se tornando professores ou cuja formação acadêmica não favorece a prática pedagógica" (BACICH; MORAN, 2017, p. 91). Os autores nos conduzem à reflexão sobre a importância de mediar as informações para que os estudantes sejam atuantes no processo, o que, na maioria das vezes, não ocorre principalmente na sala de aula que tem estudante incluído.

Na sequência do estudo, para a elaboração do material utilizado na aplicação e os conceitos a serem abordados, investigou-se o interesse dos estudantes acerca da temática abelha. Na primeira etapa, eles foram questionados sobre o que gostariam de saber sobre as abelhas. Utilizando o aplicativo Word cloud ${ }^{\circledR}$, cada estudante respondeu ao questionamento com as principais curiosidades acerca da temática. Conforme as curiosidades, uma nuvem de palavras era formada no aplicativo, que destacou as mais citadas (Figura 8). 
Figura 8: Principais curiosidades destacadas com o uso do aplicativo Word cloud®

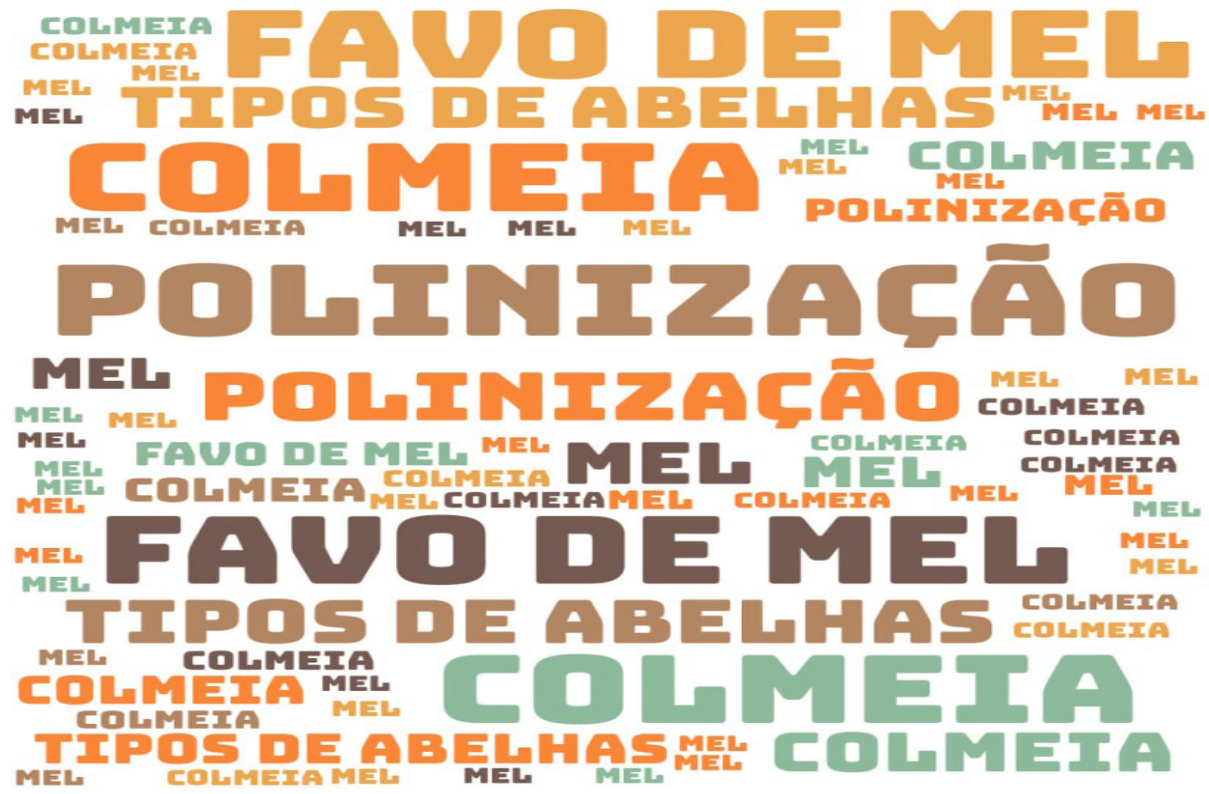

Fonte: Autoras (2019).

Após essa primeira intervenção, que buscou identificar o interesse dos estudantes sobre a temática, organizou-se a SD com o álbum seriado, jogos e maquetes, que foi aplicada em três períodos, no turno da manhã, em uma turma de sétimo ano com nove estudantes, sendo três meninos e seis meninas. Uma das estudantes apresentava baixa visão e, de acordo com relato dela, havia dificuldade em acompanhar as aulas, pois as professoras utilizavam o livro didático e o material impresso cuja fonte não era acessível. A escola tinha impressora, ela se encontrava em manutenção há algum tempo e os professores não conseguiam adaptar o material utilizado em aula.

Como forma de documentar a intervenção em sala de aula, foi utilizado o diário de campo, no qual foram registrados os momentos da aplicação da SD permitindo, além do registro, a reflexão sobre a aplicação da pesquisa. Macedo (2010) aponta que a utilização do diário de campo:

Além de ser utilizado como instrumento reflexivo para o pesquisador, o gênero diário é, em geral, utilizado como forma de conhecer o vivido dos atores pesquisados, quando a problemática da pesquisa aponta para a apreensão dos significados que os atores sociais dão à situação vivida. O diário é um dispositivo na investigação, pelo seu caráter subjetivo, intimista (MACEDO, 2010, p. 134). 
No estudo, as anotações no diário de campo foram registradas imediatamente como forma de armazenar os acontecimentos vivenciados.

Para dar início à aplicação da SD, os estudantes foram questionados sobre a atividade da apicultura: se conheciam alguém que realizasse essa atividade, onde seria o melhor lugar para colocar as caixas de abelhas e como seria a vida em uma colmeia. As respostas foram surgindo aleatoriamente e todos estudantes relataram que já avistaram caixas de abelhas e favos de mel.

Na sequência, a partir da história "Meu dia pede mel", com o álbum seriado, exploraram-se os conceitos sobre a sociedade das abelhas e a importância das flores no processo de polinização para a produção do mel. Durante a leitura dos conceitos apresentados no álbum seriado, todos os estudantes tiveram acesso ao material e a leitura foi também realizada pela estudante com baixa visão. Por meio do álbum seriado, habilidades relacionadas à leitura e à compreensão de texto foram desenvolvidas, bem como conceitos matemáticos referentes à forma hexagonal do favo de mel. A fonte ampliada permitiu que a estudante incluída tivesse acesso à leitura junto com os demais colegas utilizando o mesmo material.

Com o jogo associação das abelhas, foi possível destacar as características principais dessa classe, abordando os conceitos referentes à morfologia das abelhas, em que cada estudante deveria associar a ficha à parte do corpo correspondente. Com a observação do mel puro e a textura formada no favo de mel, os estudantes relataram suas observações em relação a esses dados. No uso do mapa tátil, os estudantes visualizaram os Estados brasileiros tentando identificá-los e logo destacando os principais produtores de mel do país, desenvolvendo, por meio do material, conceitos geográficos e matemáticos.

O jogo caminho das abelhas permitiu a abordagem dos conceitos referentes à organização social das abelhas, à polinização e à produção e mel, à utilização de agrotóxicos e ao desmatamento como as principais causas da diminuição dessa espécie. Ao abordar o impacto do uso de agrotóxicos no meio ambiente, conceitos químicos foram desenvolvidos, devido à utilização desses produtos e suas consequências em relação a diferentes espécies. Os conceitos da Física foram desenvolvidos em relação à visão das abelhas no processo de polinização. Por fim, ainda na aplicação da SD, os estudantes foram questionados acerca do porquê "Meu dia pede mel", relacionando a importância das abelhas ao meio ambiente. Nas respostas dos estudantes, destaca-se a importância das abelhas no processo de polinização e na produção do 
mel. Um estudante destacou que o mel também pode ser utilizado na fabricação de cosméticos e medicamentos. Durante a aplicação da SD, percebeu-se o envolvimento dos estudantes em relação à temática, possibilitando a reflexão acerca da atuação do ser humano no ambiente e as atitudes que podem extinguir espécies, acarretando em um desequilíbrio ambiental.

Como proposto na pesquisa, a SD se constituiu de diferentes atividades práticas em que os conceitos desenvolvidos partiram da curiosidade dos estudantes sobre a temática abelha. Para Zabala (1998), a SD:

[...] pode indicar a função que tem cada uma das atividades na construção do conhecimento ou da aprendizagem de diferentes conteúdos e, portanto, avaliar a pertinência ou não de cada uma delas, a falta de outras ou a ênfase que devemos lhe atribuir (ZABALA, 1998, p. 20).

A proposta da SD, além de diferenciar da metodologia utilizada constantemente pela professora de Ciências do contexto do estudo, abrangeu uma perspectiva de práticas mais ativas em sala de aula nas quais o estudante fosse protagonista nos processos de ensino e aprendizagem. A aprendizagem, para Bacich e Moran (2018):

[...] é ativa e significativa quando avançamos em espiral, de níveis mais simples para mais complexos de conhecimento e competência em todas as dimensões da vida. Esses avanços realizam-se por diversas trilhas com movimentos, tempos e desenhos diferentes, que se integram como mosaicos dinâmicos, com diversas ênfases, cores e sínteses, frutos das interações pessoais, sociais e culturais que estamos inseridos (p. 2).

Nesse contexto de uma aula dinâmica proporcionando uma aprendizagem ativa e significativa, buscou-se relacionar o contexto dos estudantes com conceitos a serem desenvolvidos de maneira que eles se interligassem nas diferentes áreas. Sendo o processo de aprendizagem único e diferente para cada estudante, mediar a aplicação da SD foi importante, pois, a todo o momento, os estudantes eram instigados a refletir sobre determinado assunto. Mól (2019) destaca a importância da aprendizagem:

[...] os processos de ensino e aprendizagem geram transformação de todos os envolvidos nessa interação. Para isso, o professor deve promover mediações intencionais, visando alterar a zona de desenvolvimento iminente de seus estudantes e contribuir para a formação de conceitos científicos que possibilitem o desenvolvimento de recursos cognitivos, sociais e emocionais mais eficientes para a tomada de decisões sobre si e o mundo que o cerca (p. 119).

Buscando subsídios capazes de satisfazer as particularidades dos estudantes, adaptou-se a SD para que a estudante com baixa visão tivesse acesso ao conteúdo 
da mesma forma que o restante da turma. A adaptação do material utilizado na intervenção mostra que o processo inclusivo em sala de aula se norteia na atuação do professor. Inúmeros fatores acabam impedindo que a inclusão aconteça em sala de aula, mas o principal ainda é o despreparo docente diante do processo.

Durante a elaboração e aplicação desta pesquisa, percebeu-se o afastamento existente entre a atuação da professora de Ciências e a realidade do processo inclusivo. Não há uma contextualização nos processos de ensino e aprendizagem, o que muitas vezes acaba contribuindo para as dificuldades no entendimento de conceitos científicos. Ao decorrer da aplicação da SD, a estudante com baixa visão participou ativamente das atividades propostas. Um de seus maiores obstáculos nas aulas de Ciências tratava-se das leituras dos textos no livro didático e os impressos disponibilizados pela professora sem o tamanho da fonte adequada. Durante a aplicação da SD, a estudante conseguiu ler o material disponibilizado e participar dos jogos compreendendo os conceitos que estavam sendo abordados. Conclui-se, por meio desta pesquisa, que a utilização de diferentes materiais acessíveis pode colaborar significativamente nos processos de ensino e aprendizagem de Ciências, tornando a aula mais dinâmica, com a participação ativa dos estudantes.

A proposta em torno da SD visa a uma alternativa em meio à metodologia tradicional tão presente ainda na Educação Básica. É importante salientar as inúmeras discussões que permeiam o processo de inclusão de estudantes com deficiências e as leis que amparam esse processo no Brasil. Muito se avançou em busca da inclusão de estudantes com deficiência nas escolas, mas se percebe que ainda há muito caminho a ser percorrido, pois, na escola, os estudantes têm a oportunidade de aprenderem juntos, sendo que suas diferenças não devem ser escondidas, mas respeitadas. Dessa forma, com a aplicação da SD, buscou-se contribuir de forma significativa para que a prática docente fosse reorganizada de modo a incluir todos os estudantes no processo educativo, com uma prática dinâmica favorecendo significativamente os processos de ensino e aprendizagem.

\section{Considerações finais}

A inclusão no ambiente escolar é garantida pela legislação. Tendo em vista a importância desse processo, a garantia por meios legais não é suficiente para que a verdadeira inclusão no contexto escolar aconteça, no qual inúmeros fatores 
devem ser reorganizados para que, de fato, a escola seja inclusiva. É relevante a acessibilidade no ambiente escolar para que todos tenham acesso aos ambientes da instituição, assim como a adaptação de materiais didáticos destinados aos estudantes de modo a incluir as diferenças no contexto da sala de aula. Deve ocorrer investimento em cursos de formação continuada aos professores da Educação Básica com estudantes incluídos em suas turmas, pois os relatos identificados por meio da pesquisa mostram a dificuldade de planejar e desenvolver as atividades em sala de aula com esse público.

Embora tão complexo seja o processo inclusivo na escola, mesmo diante de muitas falhas ainda existentes em relação à inclusão no nosso cotidiano, é preciso incluir as diferenças e, para isso, os professores de Ciências devem repensar sua prática em sala de aula. Esta pesquisa propôs investigar a pertinência da aplicação de uma SD sobre a temática abelha, no componente curricular de Ciências na Educação Básica. Analisou-se, por meio da aplicação de uma SD, uma dinâmica diferenciada e ativa nas aulas de Ciências, motivando os estudantes e colaborando com a professora, mostrando que, com a utilização de materiais didáticos adaptados, é possível utilizar metodologias ativas nas aulas de Ciências.

Refletindo a partir dos resultados obtidos nessa pesquisa, em nenhum momento houve a pretensão de apontar falhas em relação ao trabalho desenvolvido com a estudante incluída. Tendo em vista que o trabalho da escola pública é se adaptar a receber inúmeras diferenças no contexto escolar e, diante da inclusão, a escola está cada vez mais buscando alternativas para atender a todos os estudantes.

A professora de Ciências participante da pesquisa apontou a importância do processo inclusivo, mas destacou não se sentir apta a desenvolver um trabalho sozinha em relação a esse público. Com a estudante com baixa visão, percebeu-se a importância e a fragilidade do que realmente é incluir em sala de aula. A estudante relatou que gosta de Ciências e já ouviu muito a respeito, mas, nas aulas, muitas vezes não enxergava o material disponibilizado e a dificuldade em ler esses recursos acabava prejudicando seu entendimento sobre os conteúdos.

Percebe-se a complexidade do processo inclusivo, e nos relatos de todos os envolvidos na pesquisa, destaca-se que o contexto da sala de aula é uma rotina rápida em que perceber as características e necessidades de cada estudante que está diante de nós, não é tarefa fácil. O planejamento muitas vezes não está adequado a todos, não contemplando a perspectiva inclusiva. Espera-se que os resultados da pesquisa 
contribuam com a ampliação do debate sobre o processo de inclusão de estudantes com deficiência visual em sala de aula, além de demonstrar a necessidade de se investir em materiais didáticos acessíveis para o Ensino de Ciências da Natureza.

\section{Didactic sequence for the inclusive teaching of visually impaired students: approaching the bees theme}

\section{Abstract}

Inclusion in the school environment stems from many studies and practices which ensure the right of students to build their knowledge together. For this right to be guaranteed, the school must provide didactic-pedagogical means for the inclusive process to take place, seeking to value heterogeneity, treating everyone with the principle of equity. This work reports a research developed in a course in Natural Sciences Degree, which aimed to investigate the relevance of applying a didactic sequence on the theme of bees, in the curriculum component of Science in Basic Education. The methodology was characterized, as for the approach, as qualitative, as for the objectives as exploratory and, as for the procedures, as pedagogical intervention. It had as a locus a public school in the municipal network and as a subject a student with visual impairment enrolled in the seventh year of the school. The data were analyzed according to the Description Language methodology (BERNSTEIN, 2000). The research was developed in four stages, to better elucidate the researched context. As a result, the study showed that the inclusion of students with visual impairments in the school context is a possible reality and that the use of appropriate materials and resources, elaborated from the interests, needs, potentialities and the reality of the subjects, facilitate interaction in classroom, enabling their personal development by stimulating the search for knowledge construction.

Keywords: Natural Sciences teaching; Meaningful learning; School inclusion.

\section{Nota}

1 Disponível em: <https://sebraers.com.br/apicultura/rs-e-o-principal-produtor-de-mel-ha-mais-de-uma-decada/>. Acesso: 1 dez. 2020.

\section{Referências}

ABRAPEC. Atas do ENPEC. Disponível em: http://abrapecnet.org.br/wordpress/pt/atas-dos-enpecs. Acesso em: 10 mar. 2019.

BACICH, L.; MORAN J. Metodologias ativas para uma educação inovadora: Uma abordagem teórico-prática. Porto Alegre: Penso, 2018.

BATISTETIL, C. B. et al. Uma discussão sobre a utilização da história da ciência no Ensino de célula para alunos com deficiência visual. In: ENCONTRO NACIONAL DE PESQUISA EM EDUCAÇÃO EM CIÊNCIAS, 7, 2009, Florianópolis. Anais [...]. Santa Catarina: ABRAPEC, 2009. 
BERSCH, R. Tecnologia Assistiva - TA. In: SCIMER, C. R.; BROWNING, N.; BERSCH, R.; MACHADO, R. Atendimento Educacional Especializado: Deficiência Física. Ministério da Educação. Secretaria de Educação Especial. Brasília: [s. n.], 2007, p. 129.

BERNSTEIN, B. A estruturação do discurso pedagógico: classes, códigos e controle. Petrópolis: Vozes, 1996.

BERNSTEIN, B. Pedagogy, symbolic control and identity: theory research Critique. Revised Edition. London: Taylor and Francis, 2000.

BRASIL. DECRETO N. 7.611, DE 17 DE NOVEMBRO DE 2011. Dispõe sobre a educação especial, o atendimento educacional especializado e dá outras providências. Brasília: Casa Civil, 2011.

Ministério da Educação. Base Nacional Comum Curricular: Educação é a Base. Brasília, 2017.

BRITO, L. G. de F.; SILVA, M. G. L. A tabela periódica: um recurso para a inclusão de alunos com deficiencia visual. In: ENCONTRO NACIONAL DE PESQUISA EM EDUCAÇÃO EM CIÊNCIAS, 5, 2005, Bauru. Anais [...]. São Paulo: ABRAPEC, 2005.

CAMARGO, E. Saberes docentes para a inclusão do aluno com deficiência visual em aulas de Física. 1. ed. São Paulo: Ed. Unesp, 2012.

. Considerações sobre o ensino de física para deficientes visuais, de acordo com uma abordagem sócio-interacionista. In: ENCONTRO NACIONAL DE PESQUISA EM EDUCAÇÃO EM CIÊNCIAS, 3, 2001, Atibaia. Anais [...]. São Paulo: ABRAPEC, 2001.

. Atividade e Material Didático para o Ensino de Física à Alunos com Deficiência Visual: Queda dos Objetos. In: ENCONTRO NACIONAL DE PESQUISA EM EDUCAÇÃO EM CIÊNCIAS, 4, 2003, Bauru. Anais [...]. São Paulo: ABRAPEC, 2003.

; SILVA, Dirceu da. Trabalhando o conceito de aceleração com alunos com deficiência visual: um estudo de caso. In: SIMPÓSIO NACIONAL DO ENSINO DE FÍSICA, 15, 2003, Curitiba. Anais [...]. Curitiba: CEFET-PR, 2003.

COSTA, E. M.; LORENZETTI, L. A promoção da alfabetização científica nos anos finais do Ensino Fundamental por meio de uma sequência didática sobre crustáceos. Revista Brasileira de Ensino de Ciências e Matemática (RBECM), Passo Fundo, v. 3, n. 1, p. 11 - 47, 2020.

FREIRE, P. Pedagogia do Oprimido. 17. ed. Rio de Janeiro: Paz e Terra, 1987.

GALERY, A. A escola para todos e para cada um. São Paulo: Summus, 2017.

GALVÃO FILHO, T. A construção do conceito de Tecnologia Assistiva: alguns novos interrogantes e desafios. Revista da FACED - Entreideias: Educação, Cultura e Sociedade, Salvador, v. 2, n. 1, p. 25-42, jan./jun., 2013.

GIL, A. C. Métodos e técnicas de pesquisa social. 5. ed. São Paulo: Atlas, 1999.

Como elaborar projetos de pesquisa. 4. ed. São Paulo: Atlas, 2002.

LAVORATO, S. U. Acessibilidade nas ações educacionais a distância: um caminho para inclusão da pessoa com deficiência visual no contexto organizacional. Brasília: UCB, 2014. Dissertação (Mestrado em Gestão do Conhecimento e Tecnologia da Informação), Universidade Católica de Brasília, Brasília, 2014. 
MANTOAN, M. T. E. O direito de ser, sendo diferente na escola. In: RODRIGUES, D. (org.). Inclusão e educação: doze olhares sobre a educação inclusiva. São Paulo: Summus, 2005.

LAKATOS, E. M.; MARCONI, M. de A. Técnicas de pesquisa: planejamento e execução de pesquisas, amostragens e técnicas de pesquisas, elaboração e interpretação de dados. 3. ed. São Paulo: Atlas, 1996.

MACEDO, R. S. Etnopesquisa crítica/etnopesquisa. Brasília: Liber Livro 2010.

MÓL, G. O Ensino de Ciências na Escola Inclusiva. Brasil Multicultural, 2019.

MORAN, J. Mudando a educação com metodologias ativas. In: SOUZA, C. A. de; MORALES, E. T. (Orgs.). Convergências Midiáticas, Educação e Cidadania: aproximações jovens. Coleção Mídias Contemporâneas. 2015. Ponta Grossa: PROEX, 2015.

PIRES, R. F. M.; RAPOSO, P. N.; MÓL, G. de S. Adaptação de um livro didático de química para alunos com deficiência visual. In: ENCONTRO NACIONAL DE PESQUISA EM EDUCAÇÃO EM CIÊNCIAS, 6, 2007, Florianópolis. Anais [...]. Santa Catarina: ABRAPEC, 2007.

POLICARPO, I. As contribuições dos recursos alternativos na prática pedagógica. 2008. Disponível em: <portaldiaadiaeducacao.pr.gov.br>. Acesso em: 24 fev. 2019.

SASSAKI, R. K. Inclusão: construindo uma sociedade para todos. 8. ed. Rio de Janeiro: WVA, 2010.

SILVA, E. N.; SALGADO, A. H. I. O ensino de ciências para alunos com deficiência visual. Estariam os professores capacitados para lidar com esse público? In: ENCONTRO NACIONAL DE PESQUISA EM EDUCAÇÃO EM CIÊNCIAS, 10, 2017, Florianópolis. Anais [...]. Santa Catarina: ABRAPEC, 2017.

TRIVIÑOS, A. Introdução à pesquisa em ciências sociais: a pesquisa qualitativa em educação. São Paulo: Atlas, 1987.

VYGotsky, L. S. A construção do Pensamento e da Linguagem. São Paulo: Martins Fontes, 2001.

A Formação Social da Mente. (L. S. José Cipolla Neto, Trad.), 7 ed. São Paulo: Martins Fontes, 2007.

ZABALA, A. A prática educativa: como ensinar. [Trad. Ernani F. da Rosa]. Porto Alegre: ArtMed, 1998. 